\title{
Analytical calculation model for determining the cycle time in injection molding parts applied to design optimization algorithms
}

\author{
J. M. Mercado Colmenero ${ }^{1}$, M. A. Almazan Lazaro ${ }^{1}$, \\ C. Martin Doñate ${ }^{1}$, M. A. Rubio Paramio ${ }^{1}$, A. Vizan Idoipe ${ }^{2}$, \\ J. M. Perez Garcia 2 , J. Marquez Sevillano ${ }^{2}$ \& D. Aguilera Puerto 3 \\ ${ }^{I}$ Department of Engineering Graphics, Design and Projects, \\ Jaen University, Spain \\ ${ }^{2}$ Department of Mechanical Engineering \\ Politechnic University of Madrid, Spain \\ ${ }^{3}$ ANDALTEC Plastic Technological Center, Spain
}

\begin{abstract}
Determining the cycle time required to perform plastic parts has an important impact and relevance along the process of mold design, as well as in the cost per part. A great number of mold dimensioning algorithms and cost estimation methods use the cycle time as a main design parameter. This paper presents the results of an analytical study aimed to determine the most representative variables of the problem and how they influence in the magnitude of the cycle time. The model has been validated comparing the numerical results with the solution provided by the software Autodesk Simulation MoldFlow Advisor in several case studies. On the other hand, analytical and numerical results have been compared with dates provided by an industrial model, showing as a result a significant improvement of the accuracy of calculations. This method is intended as a complement to the use of optimization applications that require the use of a non-numerical, analytical and low computational time calculation model for determining this parameter.

Keywords: cycle time, injection molding, mold design, optimization algorithm.
\end{abstract}




\section{Introduction}

Injection molding is one of the most common plastic manufacturing process used today. In molding manufacturing process, molten row material is shaped in a mold which the resulting part must be removed after solidification. The process is suitable for volume production due to fast cycle time. The cycle time is defined as the total time taken to, inject the plastic part, pack the part in order to compensate its shrinkage during solidification, cool it to achieve enough rigidity and finally eject the part from the mold. Cycle time can be considered the major parameter in the mold design related to productivity, since it directly affects both its mechanical design and the economic benefit that the company will get during the lifetime of the part. Cycle time value is influenced by the whole mold systems (fill, heat transfer process, number of cavities, mold ejection system, etc.); each of them provide a number of parameters mutually dependent that interact with the cycle time value. Having a mathematical formulation of the cycle time can be very useful, with the purpose to use it in optimization problems for mold design. An optimal mold design and proper calculation of cycle time will allow mold makers to shorten the lead time and product cost, meeting high standards of quality and performance. The aim of this paper is to present the results of an analytical study aimed to determine the most representative variables of the problem of cycle time modelling and how they influence in the magnitude of the cycle time. This method is intended as a complement to the use of optimization applications that require the use of a non-numerical, analytical and low computational time calculation model for determining this parameter.

\section{Background}

Cycle time calculation has been approached by researchers using different analysis methods. Galantucci and Spina [1] proposed an integrated approach to evaluate gating system configurations to optimize the filling conditions of thermoplastic injection molded parts, through data integration between the finite element (FE) analysis and the design of experiment approach, however their method depends on using CAE tools as Moldflow, as well as skilled operators. Ferreira et al. [2] presented a framework, based on a Multidisciplinary Design Optimization Methodology (MDO), which tackles the design of an injection mold by integrating the structural, feeding, ejection and heat exchange subsystems to achieve significant improvements, they also perform multiple objective optimization simultaneously minimizing cycle time, wasted material and pressure drop, however they assumed that the value of the injection time is very small compared to the other times and they considered it as a constant value. Ramos et al. [3] presented a global optimization strategy for the injection molding cycle time, covering all time steps related to the injection molding process, including a novel mathematical model to predict the ejection time, however they perform calculations of injection time in the area of the cavity assuming a constant thickness of the piece (not always the part has a constant thickness) and assuming a constant value of viscosity (when this value is 
variable within the cavity), moreover they calculate the packing and cooling time in an isolated manner, when it has to be noted that the real cooling time (Menges and Walter [4]) includes packing time. This paper proposes a new model to calculate cycle time and an alternative method to calculate injection time, which focuses on the mold feeding system modeling. In this area, it is possible to introduce the value of the equivalent radius of the runners, calculating the pressure drop and the real viscosity. Moreover, the value of $R_{s}$ (equivalent radius) has been parametrized, obtaining as a result a surface that represents $R_{s}$ versus the runner flow and the value of the real radio. The ability to provide to industry, a pseudo-empirical model of innovative character for determining this parameter, represents a technological improvement in the analysis of the injection phase without using a CAE calculation method.

\section{Methodology}

Whereas the time taken to open and close the mold is analogous and, according to fig 1, the cycle time is defined by Menges and Walter [4] by the expression (1)

$$
T_{\text {Cycle }}=T_{\text {Filling }}+T_{\text {Pack }}+T_{\text {Cooling }}+T_{\text {Mold Resetting }}
$$

where $T_{\text {Filling }}$ represents the filling time, $T_{\text {Pack }}$ represents the time of packing or

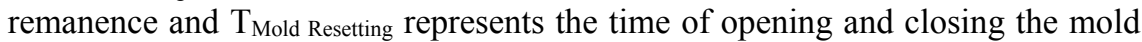
and ejection of the part.

The mold filling time, $\mathrm{T}_{\text {Filling}}$, is defined as the time needed for filling, not only the mold cavities, but also the melt distribution system (runners, sprue, gates, etc.).

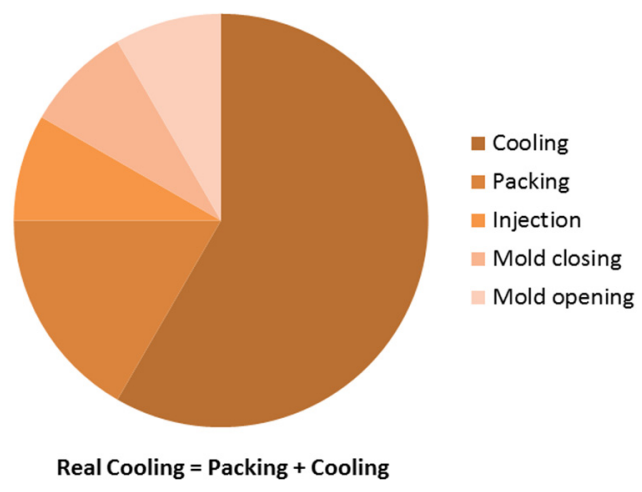

Figure 1: Main stages of injection molding.

The equation of conservation of mass amount or, in the case of fluids, continuity equation states that the flow rate through a closed system remains constant, then assuming that the pressure losses associated with the distribution channels (fig. 2) is uniform for all, then it holds eqn (2). 


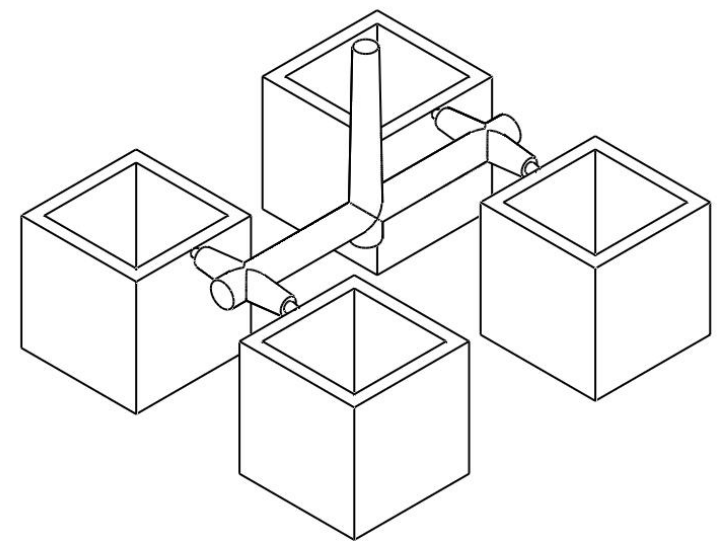

Figure 2: $\quad$ Feeding system in cavity.

$$
Q_{\text {iny }}=\sum_{i=1}^{n} Q_{\text {Cav }}(i)=n \cdot Q_{\text {Cav }} \rightarrow T_{\text {iny }}=\frac{n \cdot\left(V_{\text {Runners }}+V_{\text {Gate }}+V_{\text {Cav }}\right)+V_{\text {Sprue }}}{Q_{\text {iny }}}
$$

Evaluating the melt flow throughout a circular radius Runner section, the flow can be evaluated according to the Hagen-Pouseille equation defining a flow rate for a Newtonian fluid, eqn (3).

$$
\begin{gathered}
Q_{\text {iny }}=n \cdot Q_{\text {Cav }} \rightarrow \frac{d V(t)}{d t}=\frac{n \cdot \pi \cdot R_{S}^{4} \cdot \Delta P_{R}}{8 \cdot \mu\left(\dot{\gamma}_{S}\right) \cdot L} \\
\downarrow \\
\int_{0}^{T_{\text {iny }}} d t=\int_{0}^{n \cdot\left(V_{R}+V_{G}+V_{C}\right)+V_{S}} \frac{8 \cdot \mu\left(\dot{\gamma}_{S}\right) \cdot L}{n \cdot \pi \cdot R_{S}^{4} \cdot \Delta P_{R}} \cdot d V(t) \\
T_{\text {iny }}=\frac{V \cdot 8 \cdot \mu\left(\dot{\gamma}_{S}\right) \cdot L}{n \cdot \pi \cdot R_{S}^{4} \cdot \Delta P_{R}} \\
V=n \cdot\left(V_{\text {Runners }}+V_{\text {Gate }}+V_{\text {Cav }}\right)+V_{\text {Sprue }}
\end{gathered}
$$

where $\mathrm{V}\left[\mathrm{m}^{3}\right]$ represents the total volume of injection of the molten, $\mu\left(\dot{\gamma}_{s}\right)$ $\left[\mathrm{N} \cdot \mathrm{s} / \mathrm{m}^{2}\right]$ is the viscosity of the material, $\mathrm{L}[\mathrm{m}]$ represents the specific length of runners, $R_{S}[\mathrm{~m}]$ represents the effective radius of runners and $\Delta P_{R}\left[N / \mathrm{m}^{2}\right]$ represents the pressure loss along the runners.

As the molten plastic is considered a non-Newtonian fluid, dynamic viscosity of the material is dependent on shear stresses to which the fluid is subjected eqn (6). The shear rate of a Newtonian fluid in a tube, similar to the geometry of runners, for a nominal flow, can be defined as eqn (6):

$$
\dot{\gamma}_{S}(r)=\frac{4 \cdot Q}{\pi \cdot R^{4}} \cdot r
$$

where $\mathrm{Q}\left[\mathrm{m}^{3} / \mathrm{s}\right]$ is the injection flow of the melt and $\mathrm{R}[\mathrm{m}]$ represents the actual radius of runners. 


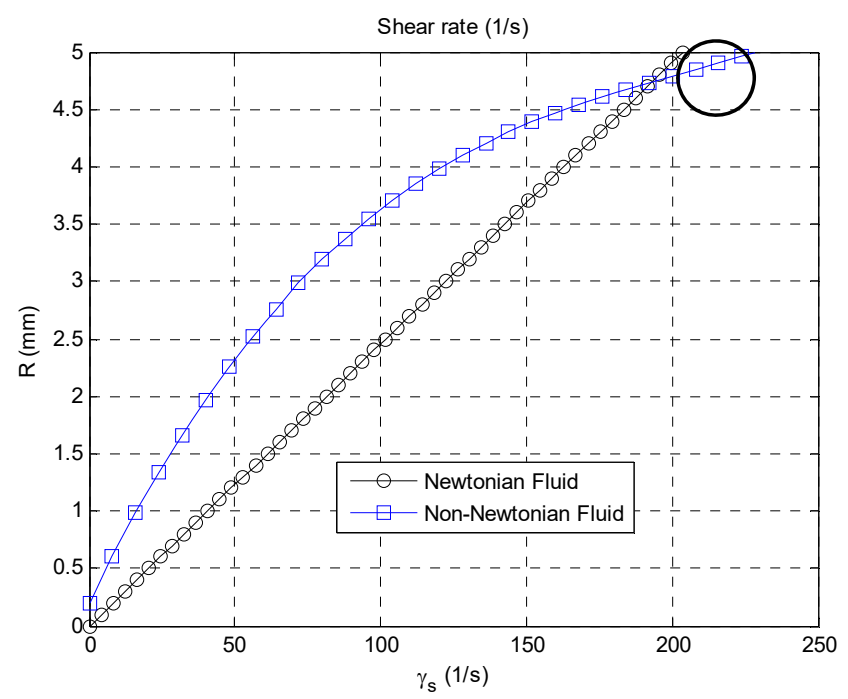

Figure 3: Shear rate distribution for a Newtonian and a non-Newtonian substance in laminar pipe flow.

But taking into fig. 3 account, it is noted that for a nominal radius of the runner, the magnitude of shear rates for a non-Newtonian fluid and a Newtonian fluid are equivalent. So for that value of effective radius, the dynamic behavior of non-Newtonian fluid may resemble to that of a Newtonian fluid (Menges and Walter [4]). This consideration allows modeling molten plastic flow according to eqn (4).

$$
R_{s} \approx e_{o} \cdot R
$$

Considering the viscosity model (Cross [5]), an empirical correlation can be established between the shear rate of non-Newtonian flow and viscosity thereof (fig. 3).

$$
\mu_{o}=D_{1} \cdot e^{\frac{-A_{1} \cdot\left(T_{m}-\bar{T}\right)}{A_{2}+\left(T_{m}-\bar{T}\right)}} \rightarrow \mu=\frac{\mu_{o}}{1+\left(\frac{\mu_{o}}{\tau} \cdot \dot{\gamma}_{s}\right)^{1-n}}
$$

where $\mu\left[\mathrm{N} \cdot \mathrm{s} / \mathrm{m}^{2}\right]$ represents the viscosity of the melt, $\mathrm{D}_{1}, \mathrm{~A}_{1}, \mathrm{~A}_{2}$ are material setting coefficients, $\mathrm{T}_{\mathrm{m}}[\mathrm{K}]$ represents the temperature of the melt front, $\overline{\mathrm{T}}[\mathrm{K}]$ represents the glass transition temperature of the material, $\tau$ represents the critical stress level at the transition to shear thinning and $\mathrm{n}$ represents the power law index in the high shear rate regime.

Thus, we can set the dynamic viscosity, and thus modeling flow within the feeding system, is dependent on the following parameters: injection rate, the geometry of the system and the type of material.

At the surface $R_{s}$ vs. R vs. Qiny (fig. 4) it has been represented the magnitude and dependence of the variable representative $R_{S}$ on the injection rate and the 
geometry of the feeding system. This has been obtained by a process of pseudoempirical analysis, from eqn (4).
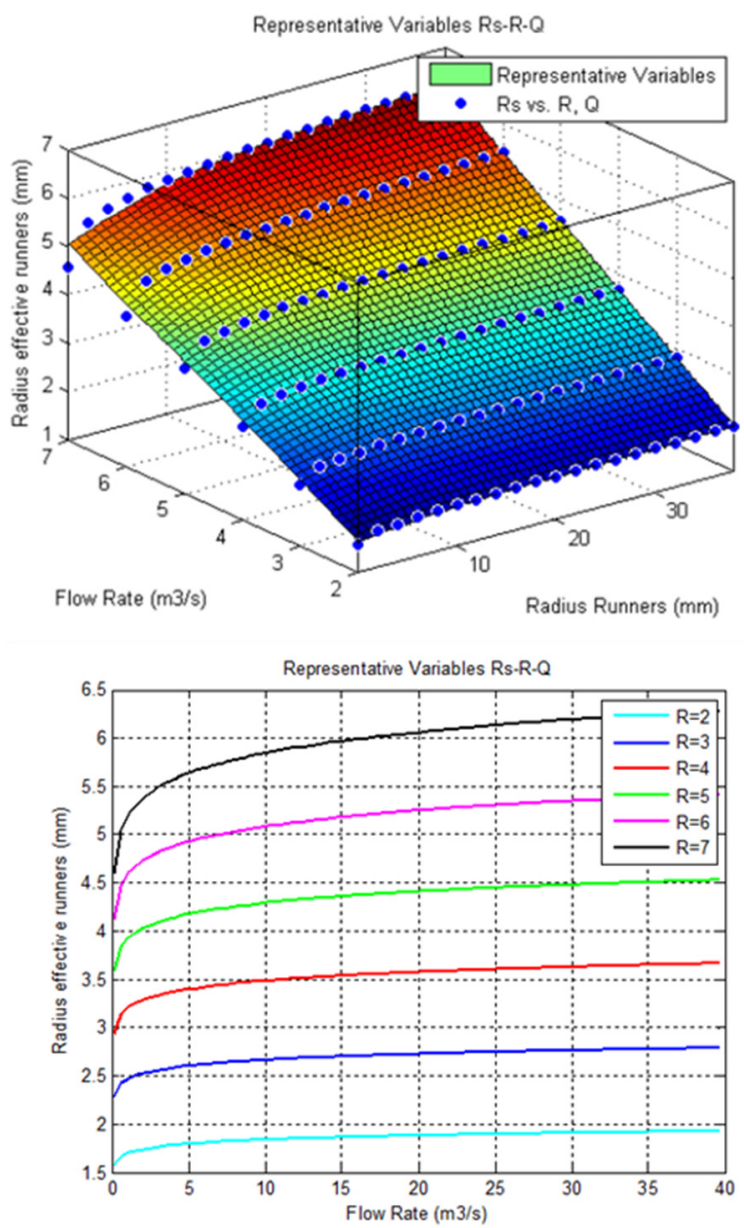

Figure 4: Surface representing the effective radius $R_{S}$ depending on the injection flow and the feeding system geometry.

The importance of this geometrical parameter associated with the analytical modeling of the injection phase is very representative because, as we can see in eqn (4), the error in assigning the actual radius of runners in the Hagen-Pouseille equation for a fluid non-Newtonian is about $\left(\mathrm{R} / \mathrm{R}_{\mathrm{S}}\right)^{4}$. Therefore, the ability to offer the industry an innovative analytical model for determining this geometric representative variable represents a technological improvement. It is not necessary to use a method of numerical calculation of CAE in the analysis of the filling phase. 
Finally, from the above graphs (fig. 4) and by eqn (4), determining the injection time and the pressure drop associated with the feeding system is trivial.

Cooling time begins when the filling phase is over, which occurs over time $\mathrm{T}_{\text {Filling. }}$ Remanence time is that which runs from the end of filling to the time of mold opening and ejection of the part, i.e. it covers the steps defined as packing and holding (compacting) and cooling, eqn (9).

$$
T_{\text {Remanence }}=t_{\text {pack }}+t_{\text {cooling }}
$$

In the compacting phase compaction pressure is held constant to compensate for shrinkage of the part caused by the cooling of the material (around $70-80 \%$ of the pressure reached in the cavity during the filling phase). Thereafter the part is cooled to the temperature of ejection. Remanence is one of the most important phases in the thermoplastics injection molding process stages, because it lasts most of the cycle time. A suitable analytical modeling of this stage provides a significant increase in accuracy.

Therefore, the time required from the end of filling the cavity until the piece reaches ejection temperature can be described by the model proposed by Menges and Walter [4].

$$
\begin{gathered}
T_{\text {Remanence }}=t_{\text {pack }}+t_{\text {cooling }}=\frac{\left(S+\delta_{\text {max }}\right)^{2}}{\pi^{2} \cdot \alpha} \cdot \operatorname{Ln}\left(\frac{4}{\pi} \cdot \frac{T_{M}-\bar{T}_{W}}{\widehat{T}_{E}-\bar{T}_{W}}\right) \\
t_{\text {pack }}=\frac{d_{\text {Gate }}^{2}}{\pi^{2} \cdot \alpha} \cdot \operatorname{Ln}\left(\frac{4}{\pi} \cdot \frac{T_{M}-\bar{T}_{W}}{\widehat{T}_{E}-\bar{T}_{W}}\right) \\
t_{\text {cooling }}=\frac{d_{\text {Sprue }}^{2}}{\pi^{2} \cdot \alpha} \cdot \operatorname{Ln}\left(\frac{4}{\pi} \cdot \frac{T_{M}-\bar{T}_{W}}{\widehat{T}_{E}-\bar{T}_{W}}\right)
\end{gathered}
$$

where $\alpha\left[\mathrm{m}^{2} / \mathrm{s}\right]$ represents the coefficient of thermal diffusivity of the material, $\mathrm{S}$ $[\mathrm{m}]$ represents the maximum wall thickness of the injection piece, $\delta$ represents dimensioning coefficient of the larger section element of the feeding system, $\mathrm{d}_{\text {Gate }}[\mathrm{m}]$ represents the gate diameter, $\mathrm{d}_{\text {sprue }}[\mathrm{m}]$ represents the diameter of the sprue, $\mathrm{T}_{\mathrm{M}}[\mathrm{K}]$ represents the temperature of the front of molten plastic, $\overline{\mathrm{T}}_{\mathrm{W}}[\mathrm{K}]$ represents the mold temperature and $\widehat{T}_{\mathrm{E}}[\mathrm{K}]$ represents the ejection temperature.

Other computational models of these two variables (Ramos et al. [3]) proposed a fragmentation of these phases. In this paper [3], a separate analysis is addressed of the compacting and cooling phases and it is proposed to establish a unified criterion of calculation based on wall thickness of the molded part geometry. Usually, the wall thickness of the injection piece is smaller than the diameter of the main elements of the feed system $\left(d_{\text {gate }}, d_{x p r u e}\right)$, therefore the time required to complete cooling (maximum thickness) of the injection piece is less than the time required for the solidification and cooling of the sprue gates. This is why dimensioning factor $\delta$ is included in eqn (10). Thus, the calculation of the actual cooling time is defined from thicker geometry of the mold assembly fig. 1 . In the case that this premise is not satisfied (wall thickness greater than the 
diameter of the sprue or gate) it is recommended not to include this parameter in the calculation.

The summatory associated with the mold opening and part ejection mold closing time is defined as the time resetting. According to the approach presented by Boothroyd et al. [6] the geometric characteristics of the part is the most important factor in this phase analysis. First, the projected area of the part and the number of cavities determine the capacity of the machine (clamp clamping force and stroke) and secondly, the maximum depth of the part influences the effective career to facilitate ejection of the part. The mold should be sized according to these parameters.

$$
t_{\text {Mold Resetting }}=1,75 \cdot t_{d} \cdot\left(\frac{2 \cdot D+0,05}{L_{M}}\right)^{1 / 2}
$$

where $t_{d}[s]$ represents the drying time of the part, $D[\mathrm{~m}]$ is the maximum cavity depth and $L_{M}[\mathrm{~m}]$ represents the clamp stokes. Eqn (13) compares the closing movement of the machine with the maximum depth of the part, increased by a technological safety factor experimentally estimate $(0.05 \mathrm{~m})$ (Boothroyd et al. [6]). This factor multiplies the drying time allotted for each operating condition of the machine in addition it is associated a factor (1.75), to compensate for the speed difference between the opening and closing operation of the mold.

\section{Case studies}

In order to validate the proposed model, cycle time has been analyzed in various scenarios. We have compared the research results with those of a commercial application of numerical calculation $\left(\right.$ MoldFlow $\left.^{\circledR}\right)$ and a cycle time calculation procedure based on industrial experience provided by the Andaltec Technological Plastic Center. These scenarios have been developed employing the plastic material Bayblent TX-85 and a $180 \mathrm{MPa}$ pressure injection machine.

Tables 1 to 4 show the results obtained in the analysis of the feeding system in the filling phase. On one hand, the results of varying the effective radius $R_{S}$ (most representative parameter in modeling molten plastic) are exposed. On the other hand, knowing the magnitude of $\mathrm{R}_{\mathrm{S}}$ and hence the effective viscosity

Table 1: Comparison of results for a runner radius of $0.002 \mathrm{~m}$.

\begin{tabular}{|c|c|c|c|c|c|}
\hline $\mathrm{Q}[\mathrm{m} / \mathrm{s}]$ & $\mathrm{Rs}[\mathrm{m}]$ & $\mathrm{e}_{\mathrm{o}}$ & $\Delta \mathrm{P}[\mathrm{Pa}]$ & $\Delta \mathrm{P}_{\text {MoldFlow } \mathbb{B}[\mathrm{Pa}]}$ & Relative error $\%$ \\
\hline 0.002 & $1.7443 \mathrm{E}-03$ & 0.8721 & $43.3676 \mathrm{E}+06$ & $43.32 \mathrm{E}+06$ & 0.11 \\
\hline 0.006 & $1.8113 \mathrm{E}-03$ & 0.9056 & $62.5389 \mathrm{E}+06$ & $60.56 \mathrm{E}+06$ & 3.28 \\
\hline 0.008 & $1.8292 \mathrm{E}-03$ & 0.9146 & $67.9364 \mathrm{E}+06$ & $64.3 \mathrm{E}+06$ & 5.66 \\
\hline 0.010 & $1.8433 \mathrm{E}-03$ & 0.9216 & $72.2313 \mathrm{E}+06$ & $67.54 \mathrm{E}+06$ & 6.95 \\
\hline 0.014 & $1.8647 \mathrm{E}-03$ & 0.9323 & $78.8969 \mathrm{E}+06$ & $73.19 \mathrm{E}+06$ & 7.80 \\
\hline 0.020 & $1.8876 \mathrm{E}-03$ & 0.9438 & $86.2334 \mathrm{E}+06$ & $80.22 \mathrm{E}+06$ & 7.50 \\
\hline 0.040 & $1.9330 \mathrm{E}-03$ & 0.9665 & $101.4169 \mathrm{E}+06$ & $97.22 \mathrm{E}+06$ & 4.32 \\
\hline
\end{tabular}


of the pseudo-plastic front, the pressure losses associated with the geometry of the feed system are shown. These results were compared and validated by numerical simulation software Moldflow ${ }^{\circledR}$.

Table 2: Comparison of results for a runner radius of $0.003 \mathrm{~m}$.

\begin{tabular}{|c|c|c|c|c|c|}
\hline $\mathrm{Q}[\mathrm{m} / \mathrm{s}]$ & $\mathrm{R}_{\mathrm{S}}[\mathrm{m}]$ & $\mathrm{e}_{\mathrm{o}}$ & $\Delta \mathrm{P}[\mathrm{Pa}]$ & $\Delta \mathrm{P}_{\text {MoldFlow }}[\mathrm{Pa}]$ & Relative error \% \\
\hline 0.002 & $2.5283 \mathrm{E}-03$ & 0.8428 & $16.4624 \mathrm{E}+06$ & $16.80 \mathrm{E}+06$ & 2.01 \\
\hline 0.006 & $2.6225 \mathrm{E}-03$ & 0.8742 & $26.8677 \mathrm{E}+06$ & $26.67 \mathrm{E}+06$ & 0.74 \\
\hline 0.008 & $2.6477 \mathrm{E}-03$ & 0.8826 & $29.9554 \mathrm{E}+06$ & $29.81 \mathrm{E}+06$ & 0.49 \\
\hline 0.010 & $2.6675 \mathrm{E}-03$ & 0.8892 & $32.4362 \mathrm{E}+06$ & $32.31 \mathrm{E}+06$ & 0.39 \\
\hline 0.014 & $2.6975 \mathrm{E}-03$ & 0.8992 & $36.3082 \mathrm{E}+06$ & $36.02 \mathrm{E}+06$ & 0.80 \\
\hline 0.020 & $2.7298 \mathrm{E}-03$ & 0.9099 & $40.5770 \mathrm{E}+06$ & $40.27 \mathrm{E}+06$ & 0.76 \\
\hline 0.040 & $2.7935 \mathrm{E}-03$ & 0.9312 & $49.3592 \mathrm{E}+06$ & $49.87 \mathrm{E}+06$ & 1.02 \\
\hline
\end{tabular}

Table 3: Comparison of results for a runner radius of $0.004 \mathrm{~m}$.

\begin{tabular}{|c|c|c|c|c|c|}
\hline $\mathrm{Q}[\mathrm{m} / \mathrm{s}]$ & $\mathrm{R}_{\mathrm{S}}[\mathrm{m}]$ & $\mathrm{e}_{\mathrm{o}}$ & $\Delta \mathrm{P}[\mathrm{Pa}]$ & $\Delta \mathrm{P}_{\text {MoldFlow } \mathbb{}}[\mathrm{Pa}]$ & Relative error \% \\
\hline 0.002 & $3.2854 \mathrm{E}-03$ & 0.8213 & $7.5681 \mathrm{E}+06$ & $7.91 \mathrm{E}+06$ & 4.32 \\
\hline 0.006 & $3.4213 \mathrm{E}-03$ & 0.8553 & $13.4468 \mathrm{E}+06$ & $12.92 \mathrm{E}+06$ & 4.08 \\
\hline 0.008 & $3.4578 \mathrm{E}-03$ & 0.8644 & $15.2893 \mathrm{E}+06$ & $14.82 \mathrm{E}+06$ & 3.17 \\
\hline 0.010 & $3.4864 \mathrm{E}-03$ & 0.8716 & $16.7894 \mathrm{E}+06$ & $16.43 \mathrm{E}+06$ & 2.19 \\
\hline 0.014 & $3.5299 \mathrm{E}-03$ & 0.8825 & $19.1536 \mathrm{E}+06$ & $18.96 \mathrm{E}+06$ & 1.02 \\
\hline 0.020 & $3.5767 \mathrm{E}-03$ & 0.8942 & $21.7743 \mathrm{E}+06$ & $21.85 \mathrm{E}+06$ & 0.35 \\
\hline 0.040 & $3.6694 \mathrm{E}-03$ & 0.9173 & $27.1410 \mathrm{E}+06$ & $28.07 \mathrm{E}+06$ & 3.31 \\
\hline
\end{tabular}

Table 4: Comparison of results for a runner radius of $0.006 \mathrm{~m}$.

\begin{tabular}{|c|c|c|c|c|c|}
\hline $\mathrm{Q}[\mathrm{m} / \mathrm{s}]$ & $\mathrm{Rs}[\mathrm{m}]$ & $\mathrm{e}_{\mathrm{o}}$ & $\Delta \mathrm{P}[\mathrm{Pa}]$ & $\Delta \mathrm{P}_{\text {MoldFlow } \mathbb{B}[\mathrm{Pa}]}$ & Relative error $\%$ \\
\hline 0.002 & $4.7265 \mathrm{E}-03$ & 0.7878 & $2.2727 \mathrm{E}+06$ & $2.483 \mathrm{E}+06$ & 8.47 \\
\hline 0.006 & $4.9688 \mathrm{E}-03$ & 0.8281 & $4.4615 \mathrm{E}+06$ & $4.464 \mathrm{E}+06$ & 0.06 \\
\hline 0.008 & $5.0343 \mathrm{E}-03$ & 0.8390 & $5.2161 \mathrm{E}+06$ & $4.966 \mathrm{E}+06$ & 5.04 \\
\hline 0.010 & $5.0857 \mathrm{E}-03$ & 0.8476 & $5.8509 \mathrm{E}+06$ & $5.635 \mathrm{E}+06$ & 3.83 \\
\hline 0.014 & $5.1641 \mathrm{E}-03$ & 0.8607 & $6.8828 \mathrm{E}+06$ & $6.782 \mathrm{E}+06$ & 1.49 \\
\hline 0.020 & $5.2486 \mathrm{E}-03$ & 0.8748 & $8.0618 \mathrm{E}+06$ & $7.979 \mathrm{E}+06$ & 1.04 \\
\hline 0.040 & $5.4168 \mathrm{E}-03$ & 0.9028 & $10.5349 \mathrm{E}+06$ & $11.11 \mathrm{E}+06$ & 5.18 \\
\hline
\end{tabular}



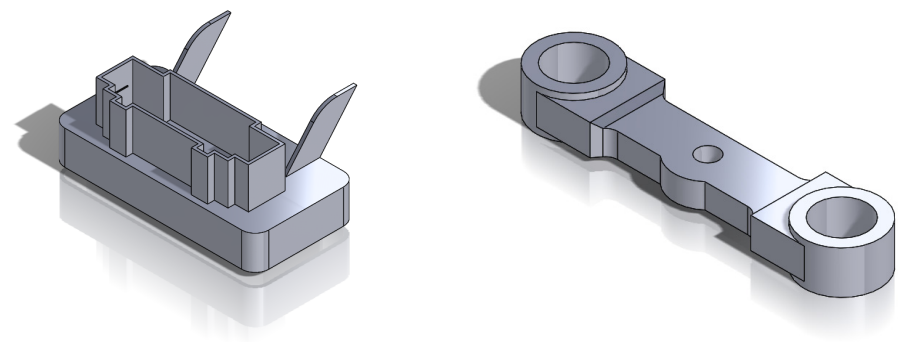

Figure 5: Geometries object of study (Part A: maximum thickness [m]: 0.010, volume $\left[\mathrm{m}^{3}\right]$ : $0.825 \mathrm{E}-03$ ); (Part B: maximum thickness [m]: 0.020, volume $\left.\left[\mathrm{m}^{3}\right]: 0.145 \mathrm{E}-03\right)$.

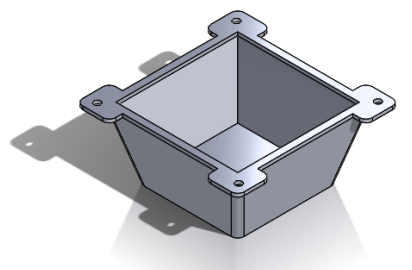

Figure 6: Geometries object of study. Part C: maximum thickness [m]: 0.010, volume $\left[\mathrm{m}^{3}\right]: 0.078 \mathrm{E}-03$.

Tables 5 to 7 show the results of cycle time obtained by implementing the proposed calculation model. In turn, these are compared with the results obtained after application of numerical simulation software Moldflow ${ }^{\circledR}$ and experimental model used in the plastics industry. The results show that the analytical approach of the proposed model fits comprehensively to the numerical results of simulation software for each phase of the cycle time, because the percentage relative error committed in the approximation ranges from 1-5\%. On the other hand, we see that empirical industrial/experimental model departs from the results, indicating a lack of representative accurate results. The minimum relative error in the approximation ranges is $25 \%$.

Table 5: Comparison of results, Part A.

\begin{tabular}{|c|c|c|c|c|}
\hline Description & Units & Analytical model & $\begin{array}{c}\text { Numerical model } \\
\left(\text { MoldFlow }^{\circledR}\right)\end{array}$ & Industrial model \\
\hline QFilling & $\mathrm{m}^{3} / \mathrm{s}$ & $0.126 \mathrm{E}-03$ & $0.128 \mathrm{E}-03$ & - \\
\hline $\mathrm{V}_{\text {Filling }}$ & $\mathrm{m}^{3}$ & $0.825 \mathrm{E}-03$ & $0.825 \mathrm{E}-03$ & $0.825 \mathrm{E}-03$ \\
\hline $\mathrm{T}_{\text {Filling }}$ & $\mathrm{s}$ & 6.55 & 6.45 & 30 \\
\hline $\mathrm{T}_{\mathrm{P} / \mathrm{H} \& \mathrm{C}}$ & $\mathrm{s}$ & 182.98 & 173.5 & 260 \\
\hline $\mathrm{T}_{\text {Cycle }}$ & $\mathrm{s}$ & 189.53 & 179.95 & 354 \\
\hline
\end{tabular}


Table 6: Comparison of results, Part B.

\begin{tabular}{|c|c|c|c|c|}
\hline Description & Units & Analytical model & $\begin{array}{c}\text { Numerical model } \\
(\text { MoldFlow }\end{array}$ & Industrial model \\
\hline QFilling $^{\mathbb{B}}$ & $\mathrm{m}^{3} / \mathrm{s}$ & $0.057 \mathrm{E}-03$ & $0.059 \mathrm{E}-03$ & - \\
\hline $\mathrm{V}_{\text {Filling }}$ & $\mathrm{m}^{3}$ & $0.145 \mathrm{E}-03$ & $0.145 \mathrm{E}-03$ & $0.145 \mathrm{E}-03$ \\
\hline $\mathrm{T}_{\text {Filling }}$ & $\mathrm{s}$ & 2.55 & 2.45 & 60 \\
\hline $\mathrm{T}_{\mathrm{P} / \mathrm{H} \& \mathrm{C}}$ & $\mathrm{s}$ & 708.68 & 697.15 & 1040 \\
\hline $\mathrm{T}_{\text {Cycle }}$ & $\mathrm{s}$ & 711.23 & 699.6 & 1326 \\
\hline
\end{tabular}

Table 7: Comparison of results, Part C.

\begin{tabular}{|c|c|c|c|c|}
\hline Description & Units & Analytical model & $\begin{array}{c}\text { Numerical model } \\
(\text { MoldFlow }\end{array}$ & Industrial model \\
\hline QFilling & $\mathrm{m}^{3} / \mathrm{s}$ & $0.078 \mathrm{E}-03$ & $0.079 \mathrm{E}-03$ & - \\
\hline $\mathrm{V}_{\text {Filling }}$ & $\mathrm{m}^{3}$ & $0.903 \mathrm{E}-03$ & $0.903 \mathrm{E}-03$ & $0.903 \mathrm{E}-03$ \\
\hline $\mathrm{T}_{\text {Filling }}$ & $\mathrm{s}$ & 11.57 & 11.49 & 30 \\
\hline $\mathrm{T}_{\mathrm{P} / \mathrm{H} \& \mathrm{C}}$ & $\mathrm{s}$ & 259.11 & 257.41 & 260 \\
\hline $\mathrm{T}_{\text {Cycle }}$ & $\mathrm{s}$ & 270.68 & 268.90 & 354 \\
\hline
\end{tabular}

\section{Conclusions and future work}

This work addresses an analytical model (non-numeric) to calculate cycle time for injection molding pieces, which improves the accuracy regarding conventional models used in industry. This model is suitable for optimization problems in mold design. The most important phases of the cycle time have been modelled, as well as the most representative parameters, including an alternative mathematical model to predict injection time. Injection time has been modelled focusing on the feeding system where the geometry of the runners, as well as the viscosity remains constant, this fact allows obtaining the effective radius; by contrast on the models centered on the cavity, where parameter values are variable because of variable part geometry.

A family of curves has been obtained that parameterizes the value of Rs depending on the injection flow and the runner radius, its usefulness being demonstrated, in optimization problems that require a non-numerical modeling. The importance of this parameter associated with the analytical modeling of the injection phase is very representative, the error has been valuated, obtaining results in the range $(80-150 \%)$, since the radius of the runner in the equation is elevated to 4 . It has been modeled the remanence phase (packing time + cooling time) and the ejection phase, setting the most significant parameters. The model has been validated comparing the numerical results with the solution provided by the software Autodesk Simulation Moldflow Advisor in several case studies. On the other hand, analytical and numerical results have been compared with dates 
provided by an industrial model, showing as a result a significant improvement of the accuracy of calculations, getting an error of $25 \%$ in the best of cases.

\section{Acknowledgement}

This work has been supported by the Consejeria de Economía, Ciencia y Empleo (Junta de Andalucia, Spain) through the project titled "A vertical design software for integrating operations of automated demoldability, tooling design and cost estimation in injection molded plastic parts. (CELERMOLD)" (Excellence Project Code: TIC-1623/2014).

\section{References}

[1] Galantucci L.M., Spina R., "Evaluation of filling conditions of injection molding by integrating numerical simulations and experimental test", Journal of Materials Processing Technology 141, 266-275 (2002).

[2] Ferreira I., De Weck O., Saraiva P., Cabral J. "Multidisciplinary Optimization of Injection molding Systems" Structural and Multidisciplinary Optimization, 41: 621-635 (2010).

[3] Ramos C.; Carreira P.; Bartolo P., Nuno A.; Optimal mould - part I. AIP Conference Proceedings 1479, 1574-1578 (2012).

[4] Menges G., Walter M. How to make injection molds, 2001, Hanser, Cincinnati.

[5] Cross M.M. "Rheology of Non-Newtonian Fluids - a New Flow Equation for Pseudoplastic Systems". Journal of Colloid Science, Vol. 20-5, pp. 417437 (1965).

[6] Boothroyd G., Dewhurst P., Knight W. Product Design for Manufacture and Assembly, 2011, CRC Press, London and New York. 